\section{Endocrinology through the changes}

\section{J.G. Phillips}

Hormones in Development and Aging. Edited by Antonia Vernadakis and Paola S. Timiras. Pp.686. ISBN 0-85200-560-1. (MTP Press: 1982.) £50.25.

REVIEW books on important and topical areas of biomedical research are always to be welcomed. Such a reception should greet Hormones in Development and Aging. Vernadakis and Timiras, the editors, have assembled an impressive group of authors to review the literature, highlight current concepts and anticipate developments in an area of endocrinology which holds great current interest both in its fundamental aspects and in its impact on clinical practice.

The overall approach has been to provide detailed coverage of the events running from fertilization through to differentiation, development, maturation and ageing, as well as of the role hormones play in organizing cellular expression and regulating metabolic events. Rightly central in the thinking of the authors has been the underscoring of the interrelationship of the endocrine and nervous systems, as both are crucially involved in the processes of growth and adaptation, puberty, rhythms of biological importance, the onset and ageing of reproductive functions, general ageing and neoplasia.

The secondary aim has been to consider the effects of hormones on brain development, both normal and abnormal, and to examine their influence on behaviour throughout the life span. This longitudinal approach allows each of the contributors to describe the basic aspects of changes in endocrinology during development and ageing, as well as pathological alterations which subtract from the optimum conditions for good health and the capacity to maintain vigour into "old age".

The authors have also seized upon the opportunity to propose interventive approaches wherever possible. This emphasis is in tune with the widely held view that, by finding means of stengthening physiological function, there will be a swing away from the current clinical practice of finding the cure for the disease towards the elaboration of a set of well understood guidelines which, when followed, will possibly serve to maintain adaptability and vigour throughout the whole life span. The clinical potential of such procedures is self-evident.

The impact of the book is unfortunately diminished by numerous errors in the text, a lack of consistency in presentation of data, poor photographs and an amazing paucity of very recent papers - indeed, it is explicitly stated that Ramaley's chapter, "Neuroendocrinology of Puberty", was written five years ago! On balance, however, this is a valuable compilation of reviews which must find its way into libraries and onto the desks of gerontologists, geriatricians and developmental biologists.

J.G. Phillips is Director of the Wolfson Institute at the University of Hull.

\section{Before Einstein}

\section{Stephen G. Brush}

Energy, Force, and Matter: The Conceptual Development of NineteenthCentury Physics. By P.M. Harman. Pp.182. Hbk ISBN 0-521-24600-8; pbk ISBN 0-521-28812-6. (Cambridge University Press: 1982.) Hbk £13.20, $\$ 27.50$; pbk $£ 5.50, \$ 8.95$.

IT IS NO easy task to give a concise, accurate and readable account of nineteenthcentury physics. Yet someone must undertake it if students and general readers are to gain an understanding of the background for the spectacular theories and discoveries of the twentieth century. In his contribution to the distinguished Cambridge History of Science Series, P.M. Harman (formerly Heimann) has satisfied the first two criteria admirably, the third passably. He has condensed an amazing amount of material into fewer than 200 pages (including a valuable bibliographic essay and a useful index); his facts and interpretations are in accord with the best modern scholarship; but his style is not lively enough to attract a reader who is not already convinced of the importance of the subject. It is probably the best textbook currently available for the first part of a course on the history of modern physics, as long as the instructor can motivate students to struggle through Harman's denselywritten prose.

Following a rapid survey of imponderable fluids, the ether concept, Fourier's heat theory and the discovery of energy-conversion processes in the first half of the century, Harman gives a thorough treatment of the development of thermodynamics and field theories of electricity and magnetism. An account of Hertz's discovery of electromagnetic waves, the Michelson-Morley experiment and Lorentz's electrodynamics prepares the reader for the introduction of relativity; but, as a professional historian striving to avoid the Whig interpretation (judging the past only as progress towards the present), Harman carefully refrains from mentioning Einstein's theory at this point. Instead, he jumps back to Dalton's chemical atomic theory and traces molecular physics through Clausius, Maxwell and Boltzmann. A final chapter ties together the late nineteenth-century critiques of atomism and the difficulties in ether theory accompanying the decline of the mechanical world view. Having pointed out the continuity between these trends of the 1890 s and the revolutionary ideas of Planck and Einstein, the author ends his story just before the conflicts in his plot are resolved.

Readers familiar with current writings in the history of science will perhaps regret that Harman has chosen to minimize the philosophical, social and psychological aspects of physics; we find here no mention of Kuhnian paradigms, Lakatosian research programmes, or (a more recent fad) Mary Douglas's grid-group categories. This is probably just as well, however, since the instructors or the more sophisticated readers will probably prefer their own version of such schemes to whatever the author might present, and it is always useful to have one straight forward account of the basic technical developments.

For me, a more serious omission is the mathematical basis of physical theories. Incredible as it might seem to a physicist, Harman manages to discuss all the abovementioned topics without using a single equation or mathematical symbol. While this policy may succeed in making the book appear accessible to a larger audience, I doubt if a phrase such as "Lagrangian formalism" will mean much to the reader who lacks knowledge of theoretical physics. On the other hand there is a definite advantage in having a mathematics-free text if the missing equations are presented and explained in a separate chapter at the end, so that those readers who wish to know, for example, what Maxwell's field equations are and how they explain the propagation of light, can find out.

For those authors who have been frustrated by the refusal of publishers to print discursive footnotes (as opposed to endnotes), the most exciting aspect of this book may be Harman's innovative use of figure captions. He displays admirable ingenuity in adding to these captions not only technical details about the experiments being illustrated, but also sociological comments and other interesting digressions that would have disrupted the flow of ideas in the text. In fact, as the caption to a reproduction of Maxwellian postcards shows (Fig. 4.5), one can even use this format to give brief explanations of important equations. As a reader who sometimes enjoys an author's footnotes more than his text, I look forward to a new era of scholarly publishing in which the most fascinating parts of a book will be found underneath its illustrations.

Stephen G. Brush is a Professor in the Department of History and the Institute for Physical Science and Technology at the University of Maryland, College Park. 